\title{
Misperceptions of weight status among adolescents: sociodemographic and behavioral correlates
}

This article was published in the following Dove Press journal:

Patient Related Outcome Measures

II December 2014

Number of times this article has been viewed

\author{
Amy E Bodde' \\ Timothy J Beebe' \\ Laura P Chen ${ }^{2}$ \\ Sarah Jenkins ${ }^{3}$ \\ Kelly Perez-Vergara ${ }^{4}$ \\ Lila J Finney Rutten ${ }^{5}$ \\ Jeanette $Y$ Ziegenfuss ${ }^{6}$ \\ 'Division of Health Care Policy and \\ Research, Mayo Clinic, Rochester, \\ MN, USA; ${ }^{2}$ Seattle Children's Hospital, \\ Seattle, WA, USA; ${ }^{3}$ Division of \\ Biomedical Statistics and Informatics, \\ Mayo Clinic, Rochester, MN, USA; \\ ${ }^{4}$ Children's Hospital, Boston, MA, USA; \\ ${ }^{5}$ Division of Epidemiology, Mayo Clinic, \\ Rochester, MN USA; ${ }^{6}$ HealthPartners \\ Institute for Education and Research, \\ Minneapolis, MN, USA
}

Objective: Accurate perceptions of weight status are important motivational triggers for weight loss among overweight or obese individuals, yet weight misperception is prevalent. To identify and characterize individuals holding misperceptions around their weight status, it may be informative for clinicians to assess self-reported body mass index (BMI) classification (ie, underweight, normal, overweight, obese) in addition to clinical weight measurement.

Methods: Self-reported weight classification data from the 2007 Current Visit Information Child and Adolescent Survey collected at Mayo Clinic in Rochester, MN, were compared with measured clinical height and weight for 2,993 adolescents.

Results: While, overall, $74.2 \%$ of adolescents accurately reported their weight status, females, younger adolescents, and proxy (vs self) reporters were more accurate. Controlling for demographic and behavioral characteristics, the higher an individual's BMI percentile, the less likely there was agreement between self-report and measured BMI percentile. Those with high BMI who misperceive their weight status were less likely than accurate perceivers to attempt weight loss.

Conclusion: Adolescents' and proxies' misperception of weight status increases with BMI percentile. Obtaining an adolescent's self-perceived weight status in addition to measured height and weight offers clinicians valuable baseline information to discuss motivation for weight loss.

Keywords: BMI, obesity, weight perception, adolescents, primary care

\section{Introduction}

Rates of childhood and adolescent obesity have increased over the past 3 decades. ${ }^{1}$ An estimated $34.1 \%$ of adolescents in the United States are overweight or obese. ${ }^{2}$ Obese adolescents are more likely than their normal weight counterparts to suffer from health issues including obstructive sleep apnea, metabolic syndrome, diabetes mellitus type 2, hyperlipidemia, orthopedic issues, asthma, and hypertension. ${ }^{3,4}$ Obese adolescents also have higher rates of emotional and social problems. ${ }^{5-7}$ The negative effects of obesity accumulate over the life course; thus, intervening to address behavioral patterns that contribute to obesity in young populations is critical. ${ }^{8,9}$

Understanding the concordance between an adolescent's perceived and actual weight classification provides insight into the risk for a number of health behaviors and psychosocial outcomes. Previous studies have shown perceptions of being overweight during adolescence to be associated with mental health problems, ${ }^{10,11}$ suicidal thoughts, ${ }^{12,13}$ problematic behaviors, and disordered eating. ${ }^{14}$ Even more concerning is that adolescents with altered body weight perception may experience more problem behavior than overweight adolescents with an accurate body weight perception. ${ }^{15}$
Correspondence: Jeanette $Y$ Ziegenfuss HealthPartners Institute for Education and Research, 8170 33rd Avenue South, Bloomington, MN 55440, USA Email jeanette.y.ziegenfuss@ healthpartners.com 
These correlates of weight misperception have been commonly studied in adolescents who are normal or underweight but misperceive themselves as overweight or obese; however, few studies have explored the correlates of overweight and obese adolescents who misperceive themselves as normal or underweight. Overweight adolescents who misperceive their weight status have been shown to be less likely to exercise or restrict calories for weight control compared to overweight adolescents who accurately perceive themselves as overweight. ${ }^{16}$ Just as an underweight or normal weight adolescent who misperceives his or her weight status may be identified for behavioral or mental health counseling, an overweight or obese adolescent who misperceives may be a candidate for weight loss counseling.

Emerging evidence suggests that there is often a discrepancy between actual weight and perceptions of weight; ${ }^{17,18}$ this discrepancy is more pronounced among overweight or obese individuals. ${ }^{16,17,19,20}$ Accurate perceptions about being overweight are an important cue for behavioral change and are associated with motivation to engage in healthy behaviors. ${ }^{21,22}$ Few studies have explored the behavioral correlates of overweight and obese adolescents who misperceive themselves as normal or underweight. We aimed to determine whether the perceived body mass index (BMI) classification is consistent with clinical height and weight measures, and to explore health behaviors among overweight or obese adolescents who misperceive their weight status.

\section{Methods}

We analyzed data from the Current Visit Information (CVI) Child and Adolescent Survey administered in 2007 to all patients or a proxy prior to clinical visit in the Mayo Clinic Community Pediatrics and Adolescent Medicine or Family Medicine departments in Rochester, MN, to assess patients' perceived health status and lifestyle. Our analysis focuses on adolescents aged 12-18 who authorized use of their medical record for research $(n=2,993)$. Perceived weight status was assessed with the question, "How does the patient describe their weight?" with the following response options: very underweight, somewhat underweight, about the right weight, somewhat overweight, very overweight. We combined the first three categories into "not overweight". Covariates included age, sex, patient vs proxy report, weight-related behavior ("Which of the following is the patient trying to do about weight?" - not trying to do anything, trying to gain weight, trying to lose weight, trying to stay the same), and reports of physical activity, television and computer use, and dietary behavior.
Clinically measured height and weight, obtained within 3 months of CVI completion, were used to calculate BMI percentile rankings, which were further determined based on Centers for Disease Control and Prevention standard growth charts. Accordingly, adolescents in the $<85$ th percentile were classified as not overweight, 85 th to $<95$ th percentile as overweight, and 95th percentile or greater as obese. Comparing the growth of children via BMI percentile rankings is more accurate than $\mathrm{BMI}$ in determining risk for health problems. ${ }^{23}$

Unless otherwise stated, self- and proxy report of BMI classification were combined. Self-reported weight classification and BMI percentile were compared to determine the percentage of cases accurately reporting weight classification. Demographic and behavioral characteristics of adolescents who were overweight or obese but misperceived their weight status were compared with those who accurately perceived their weight status.

The Mayo Clinic Institutional Review Board approved all procedures.

\section{Statistical analysis}

BMI percentiles based on the 2000 Census national population estimates were calculated using SAS software code from the Centers for Disease Control and Prevention. ${ }^{24}$ Demographic and behavioral characteristics were compared across percentile categories using chi-square tests for nominal data, analysis of variance for age, and Kruskal-Wallis tests for ordinal characteristics. Self-reported weight classification and BMI percentile category agreement was assessed with $\kappa$-statistics. Logistic regression estimated independent associations of demographic and behavioral variables with likelihood of accurate self-assessment, where "accuracy" was defined as agreement between self-reported classification and measured BMI percentile category.

Demographic characteristics and health behaviors were compared by accuracy of perception for overweight proxy reporters, overweight patient reporters, obese proxy reporters, and obese patient reporters. Patients whose clinically measured BMI percentile ranking was at or above the 85 th percentile (eg, overweight or obese) were categorized as "misperceivers" if they self-reported their weight as "very underweight," "somewhat underweight," or "about the right weight." Analyses were performed using SAS version 9 (Cary, NC).

\section{Results}

Measured BMI status classified $13.1 \%$ of respondents as obese, $16.6 \%$ as overweight, and $70.4 \%$ as not 
overweight or obese. Demographic characteristics and weight perception status are given in Table 1. Nearly three-quarters $(74.2 \%)$ of adolescents provided an accurate self-assessment of weight. This agreement is $39 \%$ more than what would be expected by chance $(\kappa=0.39$, 95\% CI $=0.36-0.41$ ).

As shown in Figure 1, females were more accurate reporters of weight than males $(\kappa=0.43,95 \% \mathrm{CI}=0.38-0.47$ and $\kappa=0.34,95 \% \mathrm{CI}=0.30-0.38$, respectively). Younger adolescents (12-15 years of age) were more accurate than older adolescents (those aged 15-18 years). Proxy reporters were $94.8 \%$ correct for not overweight, $39.5 \%$ correct for somewhat overweight, and $16.6 \%$ correct for very overweight. Self-reporting adolescents who were not overweight reported $89.2 \%$ correctly; in the somewhat overweight group, $40.5 \%$ reported correctly, and in the very overweight group, $20.5 \%$ reported correctly.

Multivariable logistic regression analyses using a forced entry method of variable selection including the covariates, described previously, demonstrated that the only significant predictors for accurate self-report of weight were BMI percentile $(P<0.0001$, reporting accuracy decreases as measured weight increases) and daily servings of chips/French fries ( $P=0.007$, more servings corresponds with a more accurate self-report).

We compared demographic and behavioral correlates of overweight and obese adolescents who misperceived themselves to be "about the right weight" or "underweight" (Table 2). Misperceivers were more likely to be male $(P<0.0001)$, less likely to be trying to lose weight, more likely to be doing nothing or trying to stay the same $(P<0.0001)$, and reported more days of 60 minutes of physical activity $(P<0.001)$.

Obese misperceivers were less likely to try to lose weight and more likely to be doing nothing or trying to stay the same $(P<0.001)$. Misperceiving proxy reports of obese patients were more likely for male patients $(P<0.001)$, less likely to be trying to lose weight, and more likely to be doing nothing or trying to stay the same $(P<0.0001)$, and were significantly more likely to report more days of 60 minutes of physical activity $(P<0.05)$. Proxy misperceivers also reported less fast food per week $(P<0.05)$.

\section{Discussion}

Observed disparities in reports of weight classification and clinical BMI percentile suggest that the more overweight the adolescent, the less likely they (or the proxies) are to be accurate regarding their BMI status. Less than half of overweight adolescents considered themselves overweight or obese. Proxy reporters were more accurate than selfreporters, overall, but less accurate for the overweight and obese adolescents. Furthermore, overweight and obese misperceivers were less likely to try to lose weight and more likely to do nothing about their weight compared to the accurate perceivers, which is congruent with previous research. ${ }^{16}$

Although not directly discernable from our data, one reason for the inaccurate weight classification may be the negative social stigma related to overweight and obesity, ${ }^{25}$ as adolescents or their proxies may not want to admit their weight concerns. It is also possible that overweight and obese adolescents may also be less interested in health and weight issues, less willing to regularly self-monitor their weight, and less aware of their weight status. Regardless of the reason for inaccuracy, erroneous self-perception of BMI has multiple consequences for adolescent health

Despite inaccuracy, self-reported BMI status can play a significant role in assessing an adolescent's self-perception of their weight. While adolescents were not necessarily accurate in their BMI classification, the majority of obese adolescents did realize that weight was a health issue. The discrepancy between obese and overweight adolescents in recognizing a weight problem highlights the added importance of targeting overweight adolescents for clinical intervention, as a larger proportion of overweight adolescents as compared to obese adolescents did not recognize their weight as a problem.

The consequences of overweight and obesity in adolescence are unfortunate. Overweight children are teased more severely and frequently than their peers, and the degree of victimization increases with the degree of obesity. ${ }^{26,27}$ Because adolescent perception of being too heavy has been linked with the widest range of problems, regardless of measured $\mathrm{BMI}$, the negative consequences of overweight and obesity may be present solely based on an adolescent's perception of their weight and not their actual measurements.

In addition to assessing an adolescent's self-perception of BMI, parent perception of BMI is also important. Accurate parental perceptions of child's BMI classification may provide adolescents with the necessary support to recognize and manage weight problems. Parental support of behavior treatments has been found to be related to increased adolescent weight loss. ${ }^{15}$ However, half of overweight and more than $75 \%$ of obese children were misclassified using parental estimates of height and weight, rather than at-home measures. ${ }^{28}$ These results suggest that parents must first be made aware 
Table I Patient characteristics by measured BMI percentile for 2,993 adolescents, Mayo Clinic 2007

\begin{tabular}{|c|c|c|c|c|c|}
\hline & $\begin{array}{l}<85 \text { th percentile (not } \\
\text { overweight) }(\mathrm{N}=2,106)\end{array}$ & $\begin{array}{l}\text { 85th to }<95 \text { th percentile } \\
\text { (overweight) }(\mathrm{N}=496)\end{array}$ & $\begin{array}{l}\text { 95th percentile + } \\
\text { (obese) }(\mathrm{N}=391)\end{array}$ & $\begin{array}{l}\text { Total } \\
(\mathrm{N}=2,993)\end{array}$ & $P$-value \\
\hline Age, mean (SD) & $15.0(1.83)$ & $15.0(1.78)$ & I4.8 (I.82) & $15.0(1.82)$ & $0.14^{a}$ \\
\hline \multicolumn{5}{|l|}{ Sex } & $<0.000 \mathrm{I}^{\mathrm{b}}$ \\
\hline $\mathrm{F}$ & I, I 86 (56.3\%) & $267(53.8 \%)$ & I 58 (40.4\%) & I,6I I (53.8\%) & \\
\hline M & $920(43.7 \%)$ & $229(46.2 \%)$ & $233(59.6 \%)$ & I,382 (46.2\%) & \\
\hline \multicolumn{5}{|l|}{ Ethnicity/race } & $0.85^{b}$ \\
\hline Other/unknown & $436(20.7 \%)$ & 97 (19.6\%) & $80(20.5 \%)$ & $613(20.5 \%)$ & \\
\hline Non-Hispanic white & $1,670(79.3 \%)$ & $399(80.4 \%)$ & $311(79.5 \%)$ & $2,380(79.5 \%)$ & \\
\hline \multicolumn{5}{|l|}{ Who filled out the form } & $0.3 \mathrm{I}^{\mathrm{b}}$ \\
\hline Patient & $507(30.1 \%)$ & II $3(29.1 \%)$ & $83(25.9 \%)$ & $703(29.4 \%)$ & \\
\hline Proxy & I, I 79 (69.9\%) & $275(70.9 \%)$ & $238(74.1 \%)$ & I,692 (70.6\%) & \\
\hline \multicolumn{5}{|l|}{ Self-reported weight } & $<0.000 \mathrm{I}^{\mathrm{b}}$ \\
\hline $\begin{array}{l}\text { Very/somewhat underweight/about } \\
\text { the right weight }\end{array}$ & I,87I (92.9\%) & $278(59.3 \%)$ & $54(14.5 \%)$ & 2,203 (77.1\%) & \\
\hline Somewhat overweight & 139 (6.9\%) & 185 (39.4\%) & $255(68.4 \%)$ & $579(20.3 \%)$ & \\
\hline Very overweight & $5(0.2 \%)$ & $6(1.3 \%)$ & $64(17.2 \%)$ & $75(2.6 \%)$ & \\
\hline \multicolumn{5}{|l|}{ Which of the following is the patient } & $<0.000 I^{\mathrm{b}}$ \\
\hline Not trying to do anything & I, I 79 (59.6\%) & $208(44.3 \%)$ & $100(27.3 \%)$ & I,487 (52.9\%) & \\
\hline Gain weight & $173(8.7 \%)$ & $16(3.4 \%)$ & $2(0.5 \%)$ & $191(6.8 \%)$ & \\
\hline Lose weight & 189 (9.6\%) & $163(34.8 \%)$ & $224(61.2 \%)$ & $576(20.5 \%)$ & \\
\hline Stay the same weight & $437(22.1 \%)$ & $82(17.5 \%)$ & $40(10.9 \%)$ & $559(19.9 \%)$ & \\
\hline \multicolumn{6}{|l|}{$7=7+$ days $/$ week) } \\
\hline $\mathrm{N}$ & 2,019 & 474 & 367 & 2,860 & \\
\hline Mean (SD) & $4.9(1.85)$ & $4.5(2.02)$ & $4.0(2.07)$ & $4.7(1.93)$ & \\
\hline Median & 5.0 & 5.0 & 4.0 & 5.0 & \\
\hline QI, Q3 & $4.0,7.0$ & $3.0,6.0$ & $3.0,5.0$ & $3.0,6.0$ & \\
\hline TV/computer/video games score & & & & & $<0.000 \mathrm{I}^{\mathrm{c}}$ \\
\hline \multicolumn{6}{|l|}{$(0=0$ hours $/$ day; $4=$ more than } \\
\hline \multicolumn{6}{|l|}{10 hours/day) } \\
\hline $\mathrm{N}$ & 2,023 & 476 & 377 & 2,876 & \\
\hline Mean (SD) & I.3 (0.64) & $\mathrm{I} .4(0.62)$ & I.7 (0.75) & $\mathrm{I} .4(0.67)$ & \\
\hline Median & 1.0 & 1.0 & 2.0 & 1.0 & \\
\hline QI, Q3 & $1.0,2.0$ & $1.0,2.0$ & $1.0,2.0$ & $1.0,2.0$ & \\
\hline \multirow{2}{*}{\multicolumn{5}{|c|}{$\begin{array}{l}\text { Servings fruit/vegetables per day score } \\
0=0 \text { servings/day: } 5=5+\text { servings/day) }\end{array}$}} & $0.003^{c}$ \\
\hline & & & & & \\
\hline $\mathrm{N}$ & 2,010 & 477 & 373 & 2,860 & \\
\hline Mean (SD) & $2.5(1.15)$ & $2.5(1.13)$ & $2.3(1.11)$ & $2.5(1.14)$ & \\
\hline Median & 2.0 & 2.0 & 2.0 & 2.0 & \\
\hline Q1, Q3 & $2.0,3.0$ & $2.0,3.0$ & $1.0,3.0$ & $2.0,3.0$ & \\
\hline Chips/French fries score & & & & & $0.39^{c}$ \\
\hline \multicolumn{6}{|l|}{ ( $0=0$ times $/$ day; $3=3+$ times $/$ day $)$} \\
\hline $\mathrm{N}$ & $\mathrm{I}, 978$ & 466 & 362 & 2,806 & \\
\hline Mean (SD) & $0.7(0.69)$ & $0.7(0.70)$ & $0.8(0.66)$ & $0.7(0.69)$ & \\
\hline Median & 1.0 & 1.0 & 1.0 & 1.0 & \\
\hline QI, Q3 & $0.0,1.0$ & $0.0,1.0$ & $0.0,1.0$ & $0.0,1.0$ & \\
\hline Sweetened drinks/pop score & & & & & $0.02^{c}$ \\
\hline \multicolumn{6}{|l|}{$(0=0$ times $/$ day; $3=3+$ times $/$ day $)$} \\
\hline $\mathrm{N}$ & 2,022 & 478 & 375 & 2,875 & \\
\hline Mean (SD) & $0.8(0.86)$ & $0.9(0.93)$ & $0.9(0.92)$ & $0.8(0.88)$ & \\
\hline Median & 1.0 & 1.0 & 1.0 & 1.0 & \\
\hline QI, Q3 & $0.0,1.0$ & $0.0,1.0$ & $0.0,1.0$ & $0.0,1.0$ & \\
\hline Fast food score $(0=0$ times/week; & & & & & $0.15^{c}$ \\
\hline \multicolumn{6}{|l|}{$7=7+$ times/week) } \\
\hline $\mathrm{N}$ & 2,023 & 466 & 371 & 2,860 & \\
\hline Mean (SD) & $1.2(1.05)$ & $\mathrm{I} .2(0.99)$ & $1.3(1.06)$ & $1.2(1.04)$ & \\
\hline Median & 1.0 & 1.0 & 1.0 & 1.0 & \\
\hline QI, Q3 & $1.0,2.0$ & $1.0,2.0$ & $1.0,2.0$ & $1.0,2.0$ & \\
\hline
\end{tabular}

Notes: Number with missing data varies from item to item. ${ }^{a} A N O V A ;{ }^{b}$ chi-square test; 'Kruskal-Wallis.

Abbreviations: ANOVA, analysis of variance; BMI, body mass index; F, female; M, male; min, minutes; SD, standard deviation; QI, quartile I; Q3, quartile 3; TV, television. 


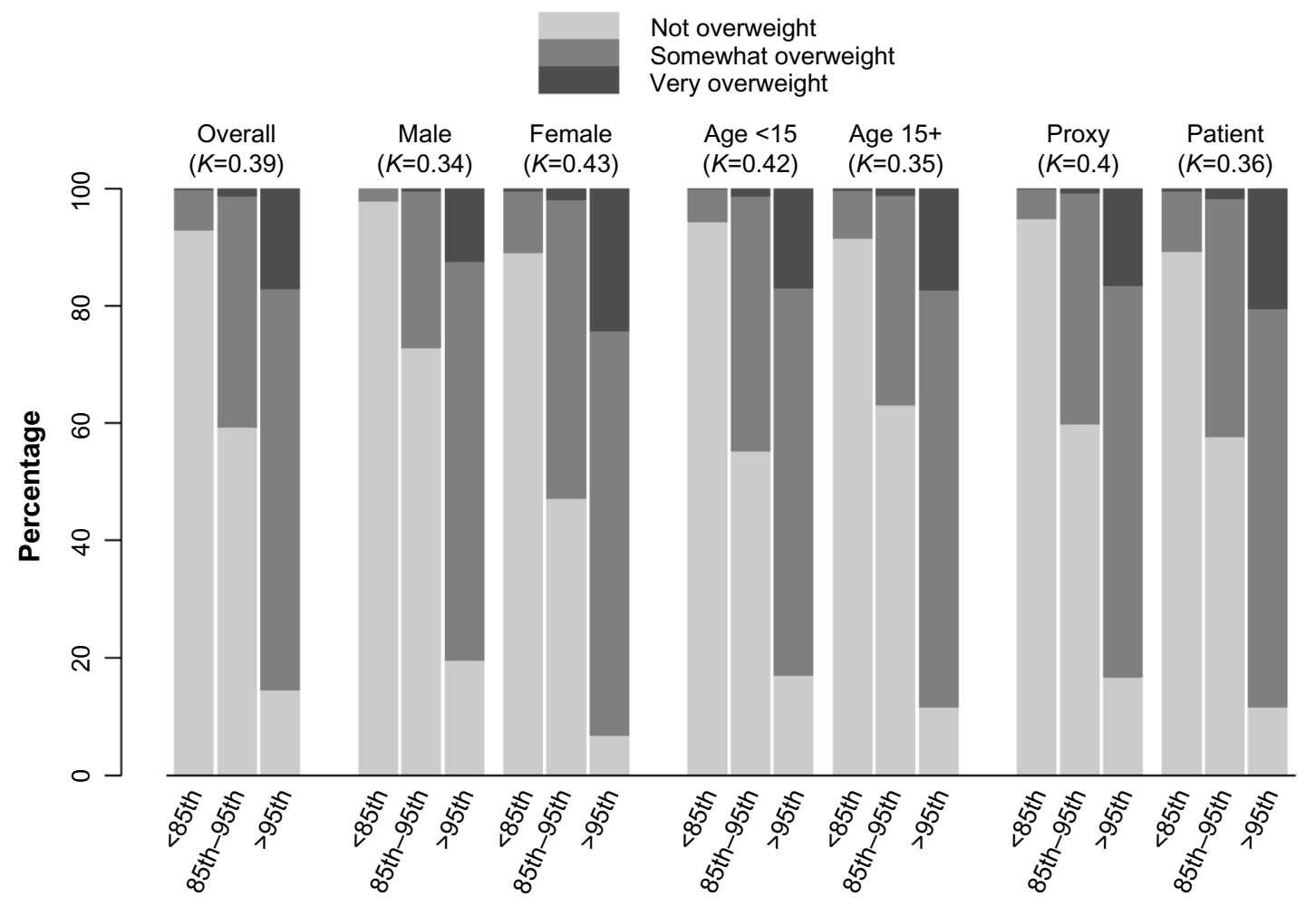

Figure I Perception of weight versus measured BMI percentile. Abbreviation: BMI, body mass index.

of a weight problem before they can be supportive of their children's weight loss goals.

In this study, we found that for all the overweight and obese misperceivers, whether patient- or proxy-reported, the patient was less likely to be trying to lose weight and more likely to be doing nothing about their weight compared to the accurate perceivers, which is congruent with prior research. ${ }^{16}$ This discrepancy could be a possible point of intervention for a clinician if an overweight/obese misperceiving patient could be identified and may benefit from a weight loss counseling technique such as follow-up with a dietitian or health educator, motivational interviewing, ${ }^{29,30}$ connection to community resources such as exercise programs, or enlisting family involvement in weight loss efforts. ${ }^{29}$ However, a seemingly contradictory finding is that, although less likely to report trying to lose weight, the overweight misperceivers (both proxy and patient) and obese proxy misperceivers reported significantly more days of adequate physical activity than the accurate perceivers. It is possible that overweight and obese misperceivers are less likely perceive a weight problem with their body because they are physically active and feel healthy, or they may be more likely to participate in organized sports than those who accurately perceive themselves as overweight or obese. Furthermore, although the
BMI measure is highly correlated to body fatness, it does sometimes misclassify people as overweight who actually have a high lean body mass (muscular overweight). ${ }^{31}$

\section{Limitations}

Data for our analyses were collected in 2007, and therefore are potentially dated. Future research is encouraged to track whether perceptions of weight vary over time or with shifts in population trends toward obesity. Other limitations stem from self-report of dietary and physical activity behavior.

\section{Practice implications}

Assessing an adolescent's self-perception of their weight also affords clinicians the opportunity to discuss any weight loss behaviors patients are undertaking. In our study population, $34.8 \%$ of overweight adolescents and $61.2 \%$ of obese adolescents were trying to lose weight. While adolescents may be attempting to lose weight, they may not be doing so in an appropriate or healthy manner. Some methods of weight loss seen in adolescents include exercise, skipping meals, taking diet pills, and vomiting. ${ }^{32}$ In a nationally representative sample of adolescents in grades 5-12, higher rates of disordered eating were observed in overweight 
Table 2 Distributions by self-reported weight for 12-18 year old overweight and obese patient and proxy reporters, Mayo Clinic 2007

\begin{tabular}{|c|c|c|c|c|c|c|}
\hline & \multicolumn{3}{|c|}{ Overweight patient reported } & \multicolumn{3}{|c|}{ Overweight proxy reported } \\
\hline & $\begin{array}{l}\text { Very/somewhat } \\
\text { underweight/ } \\
\text { about right }(\mathrm{N}=64) \\
\text { Misperceivers }\end{array}$ & $\begin{array}{l}\begin{array}{l}\text { Somewhat/very } \\
\text { overweight } \\
(\mathrm{N}=47)\end{array} \\
\text { Accurate } \\
\text { perceivers }\end{array}$ & $P$-value & $\begin{array}{l}\text { Very/somewhat } \\
\text { underweight/about } \\
\text { right }(\mathrm{N}=153) \\
\text { Misperceivers }\end{array}$ & $\begin{array}{l}\begin{array}{l}\text { Somewhat/very } \\
\text { overweight } \\
(\mathrm{N}=103)\end{array} \\
\text { Accurate } \\
\text { perceivers }\end{array}$ & $P$-value \\
\hline Age of BMI measurement & & & $0.3468^{\mathrm{a}}$ & & & $0.552 \mathrm{I}^{\mathrm{a}}$ \\
\hline $\mathrm{N}$ & 64 & 47 & & 153 & 103 & \\
\hline Mean (SD) & $16.2(1.25)$ & $16.0(1.67)$ & & $14.6(1.67)$ & $14.4(1.74)$ & \\
\hline Range & $(12.2-18.0)$ & $(12.3-18.1)$ & & $(12.0-18.1)$ & $(\mid 2.0-18.0)$ & \\
\hline Sex & & & $<0.000 \mathrm{I}^{\mathrm{b}}$ & & & $<0.000 \mathrm{I}^{\mathrm{b}}$ \\
\hline $\mathrm{F}$ & $27(42.2 \%)$ & $38(80.9 \%)$ & & $63(41.2 \%)$ & $70(68 \%)$ & \\
\hline M & $37(57.8 \%)$ & $9(19.1 \%)$ & & $90(58.8 \%)$ & $33(32 \%)$ & \\
\hline Race & & & $0.2236^{\mathrm{b}}$ & & & $0.4808^{b}$ \\
\hline Other & $7(10.9 \%)$ & $9(19.1 \%)$ & & $29(19 \%)$ & $16(\mid 5.5 \%)$ & \\
\hline White & $57(89.1 \%)$ & $38(80.9 \%)$ & & $124(81 \%)$ & $87(84.5 \%)$ & \\
\hline $\begin{array}{l}\text { Which of the following is } \\
\text { the patient trying to do } \\
\text { about his/her weight? }\end{array}$ & & & $<0.000 \mathrm{I}^{\mathrm{c}}$ & & & $<0.000 I^{c}$ \\
\hline Missing & 2 & 2 & & 5 & 3 & \\
\hline $\begin{array}{l}\text { Not trying to do anything } \\
\text { about their weight }\end{array}$ & $26(41.9 \%)$ & $12(26.7 \%)$ & & $92(62.2 \%)$ & $31(3 \mid \%)$ & \\
\hline Gain weight & $5(8.1 \%)$ & $0(0 \%)$ & & $6(4.1 \%)$ & $\mathrm{I}(\mathrm{I} \%)$ & \\
\hline Lose weight & $12(19.4 \%)$ & $32(71.1 \%)$ & & $19(12.8 \%)$ & $60(60 \%)$ & \\
\hline Stay the same weight & $19(30.6 \%)$ & $\mathrm{I}(2.2 \%)$ & & $31(20.9 \%)$ & $8(8 \%)$ & \\
\hline $\begin{array}{l}\text { 60-min physical activity (days } \\
\text { per week) }\end{array}$ & & & $0.0007^{\mathrm{a}}$ & & & $0.000 I^{a}$ \\
\hline $\mathrm{N}$ & 61 & 45 & & 146 & 100 & \\
\hline Mean (SD) & $5.0(1.83)$ & $3.8(1.83)$ & & $4.9(1.82)$ & $3.8(2.29)$ & \\
\hline Range & $(0.0-7.0)$ & $(0.0-7.0)$ & & $(0.0-7.0)$ & $(0.0-7.0)$ & \\
\hline $\begin{array}{l}\text { TV/computer/video games } \\
\text { (hours per day) }\end{array}$ & & & $0.4268^{\mathrm{a}}$ & & & $0.9420^{\mathrm{a}}$ \\
\hline $\mathrm{N}$ & 64 & 46 & & 149 & 98 & \\
\hline Mean (SD) & $1.2(0.58)$ & $1.3(0.57)$ & & $1.4(0.58)$ & $\mathrm{I} .4(0.64)$ & \\
\hline Range & $(0.0-3.0)$ & $(0.0-3.0)$ & & $(0.0-3.0)$ & $(0.0-3.0)$ & \\
\hline Servings fruit/vegetables per day & & & $0.9270^{\mathrm{a}}$ & & & $0.4727^{\mathrm{a}}$ \\
\hline $\mathrm{N}$ & 62 & 46 & & 150 & 102 & \\
\hline Mean (SD) & $2.6(1.03)$ & $2.6(1.27)$ & & $2.5(1.16)$ & $2.4(1.08)$ & \\
\hline Range & $(1.0-5.0)$ & $(1.0-5.0)$ & & $(0.0-5.0)$ & $(0.0-5.0)$ & \\
\hline $\begin{array}{l}\text { Chips/French fries } \\
\text { (times per day) }\end{array}$ & & & $0.6263^{\mathrm{a}}$ & & & $0.067 I^{\mathrm{a}}$ \\
\hline $\mathrm{N}$ & 63 & 44 & & 144 & 101 & \\
\hline Mean (SD) & $0.7(0.73)$ & $0.8(0.83)$ & & $0.6(0.67)$ & $0.8(0.65)$ & \\
\hline Range & $(0.0-3.0)$ & $(0.0-3.0)$ & & $(0.0-3.0)$ & $(0.0-2.0)$ & \\
\hline $\begin{array}{l}\text { Sweetened drinks/pop } \\
\text { (times per day) }\end{array}$ & & & $0.9748^{\mathrm{a}}$ & & & $0.6742^{\mathrm{a}}$ \\
\hline $\mathrm{N}$ & 64 & 46 & & $15 \mid$ & 99 & \\
\hline Mean (SD) & $1.0(0.95)$ & $1.0(1.06)$ & & $0.8(0.85)$ & $0.8(0.86)$ & \\
\hline Range & $(0.0-3.0)$ & $(0.0-3.0)$ & & $(0.0-3.0)$ & $(0.0-3.0)$ & \\
\hline Fast food (times per week) & & & $0.1714^{\mathrm{a}}$ & & & $0.4152^{\mathrm{a}}$ \\
\hline $\mathrm{N}$ & 63 & 45 & & 138 & 99 & \\
\hline Mean (SD) & $\mathrm{I} .0(0.8 \mathrm{I})$ & $1.2(1.38)$ & & I.I (0.88) & $1.2(0.94)$ & \\
\hline Range & $(0.0-4.0)$ & $(0.0-7.0)$ & & $(0.0-3.0)$ & $(0.0-4.0)$ & \\
\hline
\end{tabular}

Notes: ${ }^{a}$ ANOVA F-test; ${ }^{b}$ chi-square test; 'Fisher's exact test.

Abbreviations: ANOVA, analysis of variance; BMI, body mass index; F, female; M, male; min, minutes; SD, standard deviation; TV, television.

adolescents compared to non-overweight adolescents. ${ }^{33}$ Even more alarming may be that dieting behavior can be associated with an adolescent's perception of themselves as overweight, no matter whether they are truly overweight. ${ }^{34}$ Other research has shown dieting for weight control to be ineffective in adolescents and may actually promote weight gain. ${ }^{35}$ These studies demonstrate the importance of clinical input and medically supervised weight loss in adolescents who are truly overweight. Self-perception of overweight or obesity in a normal weight adolescent should trigger an 


\begin{tabular}{|c|c|c|c|c|c|c|c|}
\hline \multicolumn{4}{|c|}{ Obese patient reported } & \multicolumn{4}{|c|}{ Obese proxy reported } \\
\hline $\begin{array}{l}\text { Very/somewhat } \\
\text { underweight/ } \\
\text { about right }(\mathrm{N}=9)\end{array}$ & $\begin{array}{l}\text { Somewhat } \\
\text { overweight } \\
(\mathrm{N}=53)\end{array}$ & $\begin{array}{l}\text { Very } \\
\text { overweight } \\
(\mathrm{N}=16)\end{array}$ & \multirow[t]{2}{*}{$P$-value } & \multirow{2}{*}{$\begin{array}{l}\text { Very/somewhat } \\
\text { underweight/ } \\
\text { about right }(\mathrm{N}=\mathbf{3 8}) \\
\text { Misperceivers }\end{array}$} & $\begin{array}{l}\text { Somewhat } \\
\text { overweight } \\
(\mathrm{N}=153)\end{array}$ & $\begin{array}{l}\text { Very } \\
\text { overweight } \\
(\mathrm{N}=38)\end{array}$ & \multirow[t]{2}{*}{$P$-value } \\
\hline \multirow[t]{2}{*}{ Misperceivers } & \multicolumn{2}{|c|}{ Accurate perceivers } & & & \multicolumn{2}{|c|}{ Accurate perceivers } & \\
\hline & & & $0.3789^{a}$ & & & & $0.2444^{a}$ \\
\hline 9 & 53 & 16 & & 38 & 153 & 38 & \\
\hline $15.7(\mathrm{I} .62)$ & $16.4(1.56)$ & $16.5(1.30)$ & & $13.9(1.26)$ & I $4.4(1.70)$ & I4.3 (I.58) & \\
\hline \multirow[t]{2}{*}{$(12.5-17.5)$} & $(12.1-18.1)$ & $(13.3-17.9)$ & & $(12.1-17.3)$ & $(12.0-17.8)$ & $(12.1-17.4)$ & \\
\hline & & & $0.4427^{c}$ & & & & $0.0009^{b}$ \\
\hline $4(44.4 \%)$ & $27(50.9 \%)$ & II (68.8\%) & & $4(10.5 \%)$ & $57(37.3 \%)$ & $19(50 \%)$ & \\
\hline \multirow[t]{2}{*}{$5(55.6 \%)$} & $26(49.1 \%)$ & $5(31.3 \%)$ & & $34(89.5 \%)$ & $96(62.7 \%)$ & $19(50 \%)$ & \\
\hline & & & $0.5459^{c}$ & & & & $0.6355^{\mathrm{b}}$ \\
\hline I (II.I\%) & $12(22.6 \%)$ & 5 (3I.3\%) & & $5(13.2 \%)$ & $29(19 \%)$ & $8(21.1 \%)$ & \\
\hline \multirow[t]{2}{*}{$8(88.9 \%)$} & $4 \mathrm{I}(77.4 \%)$ & $11(68.8 \%)$ & & $33(86.8 \%)$ & $124(81 \%)$ & $30(78.9 \%)$ & \\
\hline & & & $0.0008^{c}$ & & & & $<0.000 \mathrm{I}^{\mathrm{c}}$ \\
\hline I & 0 & 0 & & I & 3 & 3 & \\
\hline $4(50 \%)$ & $10(18.9 \%)$ & $0(0 \%)$ & & $2 \mathrm{I}(56.8 \%)$ & 44 (29.3\%) & 4 (I I.4\%) & \\
\hline I (I2.5\%) & $0(0 \%)$ & $0(0 \%)$ & & $0(0 \%)$ & I (0.7\%) & $0(0 \%)$ & \\
\hline I (I2.5\%) & $36(67.9 \%)$ & 15 (93.8\%) & & $7(18.9 \%)$ & $91(60.7 \%)$ & $31(88.6 \%)$ & \\
\hline \multirow{2}{*}{$2(25 \%)$} & $7(13.2 \%)$ & $\mathrm{I}(6.3 \%)$ & & $9(24.3 \%)$ & 14 (9.3\%) & $0(0 \%)$ & \\
\hline & & & $0.0503^{a}$ & & & & $0.0490^{\mathrm{a}}$ \\
\hline 9 & 53 & 15 & & 37 & 146 & 32 & \\
\hline $5.4(\mathrm{I} .42)$ & $3.8(2.05)$ & $3.5(1.96)$ & & $4.7(1.87)$ & $3.9(2.01)$ & $3.6(2.21)$ & \\
\hline \multirow{2}{*}{$(3.0-7.0)$} & $(0.0-7.0)$ & $(1.0-7.0)$ & & $(0.0-7.0)$ & $(0.0-7.0)$ & $(0.0-7.0)$ & \\
\hline & & & $0.1879^{a}$ & & & & $0.2124^{a}$ \\
\hline 9 & 50 & 16 & & 38 & 149 & 36 & \\
\hline $2.0(1.22)$ & I.5 (0.7I) & I.8 (0.68) & & $1.6(0.68)$ & I.8 (0.80) & $1.9(0.82)$ & \\
\hline \multirow[t]{2}{*}{$(1.0-4.0)$} & $(0.0-4.0)$ & $(0.0-3.0)$ & & $(1.0-4.0)$ & $(0.0-4.0)$ & $(1.0-4.0)$ & \\
\hline & & & $0.7299^{a}$ & & & & $0.3077^{\mathrm{a}}$ \\
\hline 9 & 50 & 15 & & 38 & 148 & 37 & \\
\hline $2.6(1.33)$ & $2.2(1.17)$ & $2.2(1.26)$ & & $2.2(1.12)$ & $2.3(1.03)$ & $2.0(0.93)$ & \\
\hline \multirow[t]{2}{*}{$(1.0-5.0)$} & $(0.0-5.0)$ & $(0.0-4.0)$ & & $(1.0-5.0)$ & $(0.0-5.0)$ & $(0.0-4.0)$ & \\
\hline & & & $0.8300^{\mathrm{a}}$ & & & & $0.1774^{a}$ \\
\hline 8 & 52 & 15 & & 33 & 146 & 34 & \\
\hline $0.9(0.83)$ & $0.8(0.64)$ & $0.7(0.70)$ & & $0.6(0.56)$ & $0.7(0.66)$ & $0.9(0.87)$ & \\
\hline \multirow[t]{2}{*}{$(0.0-2.0)$} & $(0.0-2.0)$ & $(0.0-2.0)$ & & $(0.0-2.0)$ & $(0.0-3.0)$ & $(0.0-3.0)$ & \\
\hline & & & $0.7356^{a}$ & & & & $0.4563^{\mathrm{a}}$ \\
\hline 8 & 51 & 16 & & 37 & 149 & 36 & \\
\hline $0.9(0.99)$ & $1.2(1.01)$ & I.I (I.24) & & $0.8(0.86)$ & $0.8(0.83)$ & I.0 (0.99) & \\
\hline \multirow[t]{2}{*}{$(0.0-3.0)$} & $(0.0-3.0)$ & $(0.0-3.0)$ & & $(0.0-3.0)$ & $(0.0-3.0)$ & $(0.0-3.0)$ & \\
\hline & & & $0.1904^{a}$ & & & & $0.046 \mathrm{I}^{\mathrm{a}}$ \\
\hline 9 & 51 & 16 & & 38 & 144 & 36 & \\
\hline $1.9(1.17)$ & $1.4(1.02)$ & I.I (0.8I) & & I.0 (0.82) & $1.4(1.16)$ & $1.6(1.44)$ & \\
\hline$(0.0-3.0)$ & $(0.0-4.0)$ & $(0.0-3.0)$ & & $(0.0-4.0)$ & $(0.0-7.0)$ & $(0.0-5.0)$ & \\
\hline
\end{tabular}

intervention before unhealthy and unnecessary weight loss steps are undertaken.

Understanding an overweight or obese adolescent's perspective of their weight may allow providers to tailor their approach to weight loss discussions.
Motivated patients may benefit from a weight loss counseling technique such as follow-up with a dietitian or health educator, motivational interviewing, ${ }^{29,30}$ community resources for physical activity, or enlisting family involvement. $^{29}$ 


\section{Conclusion}

Accurate self- and parental perceptions of BMI classification may provide adolescents with initial motivation to manage weight problems. It may be valuable for clinicians to assess weight perception in addition to clinical weight measurement to create opportunities for clinical health promotion. Identifying weight as a health issue and taking the necessary steps toward healthy weight loss requires recognition of the issues by both clinician and patient, adolescent motivation to lose weight, and education and supervision to ensure healthy weight loss behaviors. With these steps, we can incrementally tackle the epidemic of adolescent obesity.

\section{Disclosure}

The authors report no conflict of interests in this work.

\section{References}

1. Center for Disease Control. State-Based Programs: CDC's State Based Nutrition and Physical Activity Program to Prevent Obesity and Other Chronic Diseases; 2010. Available from: http://www.cdc. gov/HealthyYouth/obesity/facts.htm. Accessed November 4, 2014.

2. Ogden C, Carroll M, Flegal K. High body mass index for age among US children and adolescents, 2003-2006. JAMA. 2008;299(20): 2401-2405.

3. Dietz W. Health consequences of obesity in youth: childhood predictors of adult disease. Pediatrics. 1998;101(3 pt 2):518-525.

4. Loke K. Consequences of childhood and adolescent obesity. Asia Pac J Clin Nutr. 2002;11(Suppl 8):S702-S704.

5. Falkner N, Neumark-Sztainer D, Story M, Jeffery R, Beuhring T, Resnick M. Social, educational, and psychological correlates of weight status in adolescents. Obes Res. 2001;9(1):32-42.

6. Swallen K, Reither E, Haas S, Meier A. Overweight, obesity, and healthrelated quality of life among adolescents: the National Longitudinal Study of Adolescent Health. Pediatrics. 2005;115(2):340-347.

7. Gortmaker S, Must A, Perrin J, Sobol A, Dietz W. Social and economic consequences of overweight in adolescence and young adulthood. N Engl J Med. 1993;329(14):1008-1012.

8. Whitaker R, Wright J, Pepe M, Seidel K, Dietz W. Predicting obesity in young adulthood from childhood and parental obesity. $N$ Engl J Med. 1997;337(13):869-873.

9. Wright C, Parker L, Lamont D, Craft A. Implications of childhood obesity for adult health: findings from thousand families cohort study. BMJ. 2001;323(7324):1280-1284.

10. Al Mamun A, Cramb S, McDermott BM, O'Callaghan M, Najman JM, Williams GM. Adolescents' perceived weight associated with depression in young adulthood: a longitudinal study. Obesity (Silver Spring). 2007;15(12):3097-3105.

11. Isomaa R, Isomaa AL, Marttunen M, Kaltiala-Heino R, Bjorkqvist K. Longitudinal concomitants of incorrect weight perception in female and male adolescents. Body Image. 2011;8(1):58-63.

12. Cook SJ, MacPherson K, Langille DB. Far from ideal: weight perception, weight control, and associated risky behaviour of adolescent girls in Nova Scotia. Can Fam Physician. 2007;53(4): 678-684.

13. Whetstone LM, Morrissey SL, Cummings DM. Children at risk: the association between perceived weight status and suicidal thoughts and attempts in middle school youth. $J$ Sch Health. 2007;77(2):59-66; quiz 98-99.
14. Eichen DM, Conner BT, Daly BP, Fauber RL. Weight perception, substance use, and disordered eating behaviors: comparing normal weight and overweight high-school students. $J$ Youth Adolesc. 2012;41(1):1-13.

15. Jelalian E, Hart C, Lloyd-Richardson E, Mehlenbeck R, Neill M, Wing R. Influence of parent behaviors on adolescent weight control. Obesity. 2009;17:S193-S194.

16. Edwards NM, Pettingell S, Borowsky IW. Where perception meets reality: self-perception of weight in overweight adolescents. Pediatrics. 2010;125(3):e452-e458.

17. Viner RM, Haines MM, Taylor SJ, Head J, Booy R, Stansfeld S. Body mass, weight control behaviours, weight perception and emotional well being in a multiethnic sample of early adolescents. Int J Obes (Lond). 2006;30(10):1514-1521.

18. John U, Hanke M, Grothues J, Thyrian JR. Validity of overweight and obesity in a nation based on self-report versus measurement device data. Eur J Clin Nutr. 2006;60(3):372-377.

19. Kuchler F, Variyam JN. Mistakes were made: misperception as a barrier to reducing overweight. Int J Obes (Lond). 2003;27(7):856-861.

20. Paeratakul S, White MA, Williamson DA, Ryan DH, Bray GA. Sex, race/ethnicity, socioeconomic status, and $\mathrm{BMI}$ in relation to selfperception of overweight. Obes Res. 2002;10(5):345-350.

21. Baranowski T, Cullen KW, Nicklas T, Thompson D, Baranowski J. Are current health behavioral change models helpful in guiding prevention of weight gain efforts? Obes Res. 2003;11(Suppl):23S-43S.

22. Rhee KE, DeLago CW, Arscott-Mills T, Mehta SD, Davis RK. Factors associated with parental readiness to make changes for overweight children. Pediatrics. 2005;116(1):E94-E101.

23. Center for Disease Control. Healthy Weight: Assessing your Weight: BMI: About BMI for Children and Teens; 2009. Available from: http:// www.cdc.gov/healthyweight/assessing/bmi/childrens_bmi/about_childrens_bmi.html. Accessed November 4, 2014.

24. CDC. A SAS Program for the 2000 CDC Growth Charts (Ages 0 to $<20$ y); 2014. Available from: http://www.cdc.gov/nccdphp/ dnpa/growthcharts/resources/sas.htm\#PDF. Accessed August 9, 2010.

25. Puhl RM, Latner JD. Stigma, obesity, and the health of the nation's children. Psychol Bull. 2007;133(4):557-580.

26. Griffiths LJ, Wolke D, Page AS, Horwood JP. Obesity and bullying: different effects for boys and girls. Arch Dis Child. 2006;91(2): $121-125$.

27. Hayden-Wade HA, Stein RI, Ghaderi A, Saelens BE, Zabinski MF, Wilfley DE. Prevalence, characteristics, and correlates of teasing experiences among overweight children vs non-overweight peers. Obes Res. 2005;13(8):1381-1392.

28. Huybrechts I, De Bacquer D, Van Trimpont I, De Backer G, De Henauw S. Validity of parentally reported weight and height for preschool-aged children in Belgium and its impact on classification into body mass index categories. Pediatrics. 2006;118(5):2109-2118.

29. Barlow SE. Expert committee recommendations regarding the prevention, assessment, and treatment of child and adolescent overweight and obesity: summary report. Pediatrics. 2007;120(Suppl 4):S164-S192.

30. Resnicow K, Davis R, Rollnick S. Motivational interviewing for pediatric obesity: conceptual issues and evidence review. J Am Diet Assoc. 2006;106(12):2024-2033.

31. Demerath EW, Schubert CM, Maynard LM, et al. Do changes in body mass index percentile reflect changes in body composition in children? Data from the Fels Longitudinal Study. Pediatrics. 2006;117(3): e487-e495.

32. Serdula MK, Collins ME, Williamson DF, Anda RF, Pamuk E, Byers TE. Weight control practices of US adolescents and adults. Ann Intern Med. 1993;119(7 pt 2):667-671.

33. Neumark-Sztainer D, Hannan PJ. Weight-related behaviors among adolescent girls and boys: results from a national survey. Arch Pediatr Adolesc Med. 2000;154(6):569-577. 
34. Strauss RS. Self-reported weight status and dieting in a cross-sectional sample of young adolescents: National Health and Nutrition Examination Survey III. Arch Pediatr Adolesc Med. 1999;153(7):741-747.
35. Field AE, Austin SB, Taylor CB, et al. Relation between dieting and weight change among preadolescents and adolescents. Pediatrics. 2003;112(4):900-906.

Patient Related Outcome Measures

\section{Publish your work in this journal}

Patient Related Outcome Measures is an international, peer-reviewed, open access journal focusing on treatment outcomes specifically relevant to patients. All aspects of patient care are addressed within the journal and practitioners from all disciplines are invited to submit their work as well as healthcare researchers and patient support groups.
The manuscript management system is completely online and includes a very quick and fair peer-review system. Visit http://www.dovepress. com/testimonials.php to read real quotes from published authors.

Submit your manuscript here: http://www.dovepress.com/patient-related-outcome-measures-journal 